\title{
"Rompendo as porteiras para poder construir algo diferente": mulheres camponesas na universidade
}

\author{
"Rompiendo puertas para poder construir algo diferente": \\ mujeres campesinas en la universidad \\ "Breaking through the gates to build something different": \\ Provincial women at the university
}

\author{
Magno Nunes Farias ${ }^{1}$ \\ Wender Faleiro ${ }^{2}$ \\ Aldanice Martins Borges Neiva ${ }^{3}$
}

Recibido: 4 de marzo 2021 • Enviado para modificación: 26 de abril 2021 • Aceptado: 8 de mayo 2021

Farias, M. N., Faleiro, W. y Borges Neiva, A. M. (2021). "Rompendo as porteiras para poder construir algo

diferente": mulheres camponesas na universidade. Revista Ocupación Humana, 21(1), 27-41. https://doi.

org/10.25214/25907816.1074

\section{RESUMO}

O estudo que deu origem a esse artigo teve como objetivo conhecer as narrativas de mulheres camponesas inseridas na universidade pública, e apreender as lutas e desafios que perpassam essas vivências. Trata-se de pesquisa qualitativa, em que se realizou um grupo focal com cinco mulheres camponesas de uma comunidade rural do município de Catalão-Goiás (Brasil), que ingressaram na Licenciatura em Educação do Campo, na Universidade Federal de Goiás/Regional Catalão. Observou-se, a partir das falas das mulheres, as dimensões materiais das dificuldades de permanência na universidade, denunciando a carência de ações para a inclusão dessas pessoas nesse espaço. As participantes apontam como o machismo interfere nos seus cotidianos, exemplificados em narrativas sobre a desconfiança dos maridos e vizinhos sobre o que elas fazem na universidade. Muitas apontam a Educação Superior como um espaço promotor de um

\footnotetext{
1 Terapeuta ocupacional. Magíster y doctor en Educación. Laboratorio Metuia, Universidade Federal de São Carlos. São Paulo, Brasil. magnonfarias@hotmail.com id http://orcid.org/0000-0002-9249-1497

2 Pedagogo. Magíster en Ecología y Conservación de Recursos Naturales. Doctor en Educación. Profesor, Universidade Federal de Catalão. Catalão, Brasil. wender.faleiro@gmail.com (iD) https://orcid.org/0000-0001-6419-296X

3 Licenciada en Educación del Campo. Universidade Federal de Catalão. Catalão, Brasil. aldanicemartinsborgesneiva@hotmail.com fiD https://orcid.org/0000-0003-4665-8548
} 
processo de emancipação, possibilitando a ocupação de outros lugares na sociedade, indo além do que é socialmente imposto, podendo se apropriar de outros saberes e experiências.

\section{PALAVRAS-CHAVE}

estudos de gênero, ensino superior, população rural, participação social

\section{RESUMEN}

El objetivo del estudio fue conocer las narrativas de mujeres campesinas que ingresan a la universidad pública y comprender las luchas y los desafíos que impregnan estas experiencias. Es una investigación cualitativa en la cual se realizó un grupo focal con cinco mujeres campesinas de una comunidad rural de Catalão-Goiás, en Brasil, quienes se unieron a la Licenciatura en Educación del Campo de la Universidad Federal de Goiás / Regional Catalão. En los discursos de las mujeres se identifican las dimensiones materiales de las dificultades relacionadas con su permanencia en la universidad, denunciando la falta de acciones para su inclusión en este espacio. Las participantes señalan cómo el machismo interfiere en su vida cotidiana, ejemplificado en narraciones sobre la desconfianza de sus esposos y vecinos sobre lo que hacen en la universidad. Sitúan la educación superior como un espacio que promueve un proceso de emancipación, permitiéndoles ocupar otros lugares en la sociedad, más allá de los que se les imponen socialmente. Además, les da la posibilidad de apropiarse de otros conocimientos y experiencias.

\section{PALABRAS CLAVE}

estudios de género, educación superior, población rural, participación social

\section{RESUMO}

The study aims to know the narratives of provincial women who attend a public university and understand the struggles and challenges that permeate these experiences. This is a qualitative study of a focus group composed of five women from the rural community of Catalão-Goiás, enrolled in the Rural Education program at the Federal University of Goiás/ Regional Catalão (Brazil). The women's narratives identify the material difficulties of staying at the university and denounce the lack of actions to include them in this space. The participants highlight how sexism interferes with their daily lives, exemplified in narratives about their husbands and neighbors' distrust about what they do at the university. Many point to higher education as a space that promotes emancipation, enabling them to occupy other places in society beyond what is socially imposed. It also allows them to acquire new knowledge and experiences.

\section{KEYWORDS}

gender studies, higher education, rural population, social participation 


\section{Introdução}

Grandes são os desafios que perpassam viver no território rural, marcado pela ausência de bens sociais, como por exemplo, o acesso à educação, desde a educação básica até a superior. Nesse processo histórico que demarca esse território há as especificidades que perpassam as mulheres rurais, que pelos processos de subalternização impostos pelo patriarcado e machismo têm suas possibilidades de vida, muitas vezes, condicionadas (Heredia \& Cintrão, 2006). Nessas dinâmicas, essas pessoas são sujeitos que têm suas vivências obstaculizadas por serem mulheres e por estarem no território rural, inclusive no que diz respeito ao acesso e à permanência na Educação Superior.

Assim, o objetivo deste estudo é conhecer as narrativas de mulheres camponesas que estão inseridas em uma universidade pública, com a finalidade de compreender as lutas e desafios que perpassam essas vivências.

Busca-se entender essas questões a partir dos referenciais teóricos dos marcadores sociais da diferença (Zamboni, 2014; Melo et al., 2020). Marcadores esses que envolvem o gênero, no recorte de mulheres, e a territorialidade, no recorte do território rural/camponês, tendo em vista o acesso e a permanência na universidade, no caso, em um curso de Licenciatura ${ }^{4}$ em Educação do Campo na realidade brasileira.

\section{Educação e população camponesa}

Existe um problema histórico de barreiras de acesso à educação para a população do campo no Brasil. Leite (1999) afirma:

A educação rural no Brasil, por motivos socioculturais, sempre foi relegada a planos inferiores, e teve por retaguarda ideológica o elitismo acentuado do processo educacional aqui instalado pelos jesuítas e a intepretação política-ideológica da oligarquia agrária conhecida popularmente na expressão: 'gente da roça não carece de estudos. Isso é coisa de gente da cidade' (p.14).

O que se estabeleceu ao longo do século XX foram formas de educação formal para os povos rurais, que foram marcadas pela precarização, urbanocentrismo e instrumentalismo, que, de grosso modo, perpassou hegemonicamente ${ }^{5}$ : o ruralismo pedagógico, no começo do século $X X$, que, de forma interessante, começou a compreender as especificidades do rural, porém, tinha como objetivo fixar os sujeitos no campo, evitando o êxodo rural, e ainda sob uma ideia urbanocêntrica e essencialista de educação; e a educação rural, potencializada na década de 1950, com o objetivo de formar mão-de-obra precarizada para atuar no processo de industrialização e moderni-

\footnotetext{
${ }^{4}$ No Brasil, a licenciatura é uma modalidade de curso superior que habilita o estudante a ser professor em escolas de Ensino Infantil, Ensino Fundamental, Ensino Médio e Ensino Técnico. Especialmente, a Licenciatura em Educação do Campo é voltada para a formação de professores para atuarem em escolas que atendam às populações do campo, no Ensino Fundamental e no Ensino Médio.

${ }^{5}$ Cabe destacar que essas são as que se estabeleceram como hegemônicas, como exemplo, as ações de educação popular junto à população rural de Paulo Freire, que se caracterizou como um processo contra-hegemônico muito importante na história.
} 
zação do campo (Farias \& Faleiro, 2019). Silva et al. (2012) reafirmam o caráter desumanizador, urbano e instrumental dessas duas perspectivas de educação para o campo.

Desumanizador por se configurar em práticas pedagógicas que negam os sujeitos-povos do campo como capazes de produzir cultura, história, saberes válidos, fragilizando a sua condição de ser humano. Urbano por ser pensada por sujeitos da cidade a se utilizar da lógica urbana. Instrumental porque objetiva o atendimento restrito das necessidades imediatas das atividades econômicas sob a lógica do capitalismo (p. 424).

Essas dificuldades históricas e conjunturais de acesso à educação, desde a básica até a superior, podem ser percebidas em alguns dados da Pesquisa Nacional por Amostra de Domicílios, elaborada pelo Instituto de Pesquisa Econômica Aplicada (IPEA, 2017). Esta pesquisa mostra que em 2015, dentre a população de 18 a 29 anos: 4,0\% das pessoas sem instrução eram rurais, enquanto 1,9\% eram urbanos; já os sem Ensino Fundamental eram 34,7\% rurais e 13,5\% urbanos; e sobre o Ensino Médio aponta que $61,4 \%$ das pessoas do território rural não cursaram esse nível de ensino, enquanto $35,1 \%$ das urbanas estão nessa situação. Assim, esses dados elucidam a desigualdade posta entre esses dois territórios.

Outro aspecto alarmante diz respeito ao fechamento das escolas rurais. Em 2002, havia 107.432 escolas no meio rural, já no ano de 2010, esse número baixou para 79.723 escolas (IPEA, 2012). Em relação à Educação Superior "a diferença entre as taxas líquidas de matrícula na Educação Superior das populações urbana $(19,9 \%)$ e rural $(6,5 \%)$ foi de 13,4 pontos percentuais em 2015" (Observatório do Plano Nacional de Educação [OPNE], 2019, s.p.). Esses dados exemplificam a negligência histórica e atual na oferta de subsídios da educação em território rural.

Essas questões ganham outra dimensão a partir das lutas constituídas pelo Movimento de Educação do Campo no Brasil, iniciadas mais fortemente nas décadas de 1980/1990, que passam a reivindicar, tendo como protagonistas os Movimentos Sociais do Campo, uma educação que dialogasse com as especificidades dos territórios e povos rurais, atrelada à democratização da terra e a um projeto societário popular e emancipatório (Farias \& Faleiro, 2019). De acordo com Caldart (2019), a Educação do Campo é constituída por "sujeitos de diferentes lutas sociais que se associam com a finalidade de organizar uma luta comum: a luta do povo que vive e trabalha no campo pelo acesso à educação pública, o qual historicamente lhes tem sido negado" (p. 59).

Nesse processo histórico, mesmo que insuficientes, ocorrem vários avanços importantes no âmbito das políticas públicas de ordem federal, em prol da democratização da educação formal no território rural brasileiro. Exemplo disso é o Programa Nacional de Educação na Reforma Agrária - PRONERA, que desde 1998 vem articulando iniciativas que possibilitaram o acesso à educação de uma grande parcela da população rural, inclusive na Educação Superior. Além disso, há o Programa de Apoio à Formação Superior e Licenciatura em Educação do Campo PROCAMPO, aprovado em 2006, configurado dentro de uma política de ações 
afirmativas, que teve como premissa garantir a entrada da população camponesa nas instituições de Ensino Superior públicas nas Licenciaturas em Educação do Campo, com processos seletivos específicos, dada a extrema fragilidade histórica das escolas rurais. Até 2015, já havia 42 cursos em todo o país (Molina, 2015; Faleiro \& Farias, 2017).

Assim, mesmo que de forma limitada, há outra inserção da população camponesa nas universidades, inclusive das mulheres camponesas. Especificamente em relação à implementação das Licenciaturas em Educação do Campo, estudos mostram que essas tiveram um papel importante para a inserção de mulheres que vivem nos territórios rurais na universidade (Faleiro \& Farias, 2017; Froes, 2017; Pereira, 2014, 2016).

Em pesquisas realizadas por Faleiro e Farias (2017) e Froes (2017), com mulheres estudantes da Licenciatura em Educação do Campo, os dados apontam como o ingresso no curso foi importante e potente na vida dessas pessoas, mas que trouxe diversos desafios, tendo em vista os marcadores sociais de gênero e territorialidade. Em diálogo com estes estudos está a investigação de Pereira (2014, 2016), que afirma que as mulheres rurais que passam por esses cursos indicam que essa vivência potencializou movimentos de resistências às relações de discriminação em seus cotidianos.

\section{Mulheres e território rural}

Os marcadores sociais de gênero ${ }^{6} \mathrm{e}$ territorialidade (no caso em tela o gênero mulher e o território rural) são essenciais nos debates colocados aqui, entendendo que esses marcadores são indissociáveis para compreender as narrativas das mulheres rurais. De acordo com Gomes et al. (2016), esse estudo "parte do (re)conhecimento dos contextos rurais em suas especificidades, de modo a compreender como ali se produzem as condições e os modos de vida das mulheres" (p. 116).

Godoi \& Aguiar (2018), ao pesquisarem mulheres e políticas de desenvolvimento rural, afirmam que o espaço rural não é homogêneo, é resultado da história e das relações de poder que ali operam, com agentes que são homens e mulheres. Nessa realidade, a participação e o protagonismo social perpassam conflitos de classe, gênero, raça-etnia, entre outros. Nisso, uma das desigualdades que se destacam está relacionada ao gênero, em que as mulheres estão em desvantagem no protagonismo das ações e no reconhecimento. Em relação a ser mulher e camponesa, Heredia \& Cintrão (2006) colocam:

As desigualdades de gênero na zona rural brasileira se inscrevem num conjunto de outras desigualdades sociais, que se expressam historicamente quando se compara a população rural e a população urbana, bem como na comparação entre as diferentes regiões do país. Assim, a análise das desigualdades e das condições de vida das mulheres rurais deve levar em conta as péssimas condições de vida e de acesso a políticas públicas nas zonas rurais, especialmente nas regiões mais pobres do país, que afetam sobremaneira as mulheres rurais,

\footnotetext{
${ }^{6}$ Em consonância com Zamboni (2014) compreende-se que gênero contempla os marcadores sociais que perpassam o ser mulher, homem, travesti, transexual etc. No caso aqui colocado, isso se observa nas especificidades das mulheres.
} 
aprofundando ainda mais as desigualdades específicas de gênero (p. 2).

Assim, compreende-se aqui o gênero como um marcador social da diferença, que é produzido socialmente como um sistema de classificação (Zamboni, 2014), que determina uma posição social de desigualdade entre homens e mulheres, na sociedade em geral (Grandón-Valenzuela, 2018). Como se analisa aqui, o território rural já se configura como um espaço historicamente marginalizado, sendo outro marcador social que produz desigualdades.

Brumer (2004) ao pesquisar a inserção de mulheres na agricultura familiar, destaca que, estas, ocupam uma posição subalternizada na divisão do trabalho, "seu trabalho geralmente aparece como 'ajuda', mesmo quando elas trabalham tanto quanto os homens ou executam as mesmas atividades que eles" (p. 210). Seus trabalhos são invisíveis e elas possuem poucos lugares de decisão. Suas funções estão mais atreladas ao cuidado dos animais (alimentação, limpeza e ordenha), limpeza da terra, colheita e trabalho na horta (para consumo da própria família), entre outros.

Nessas dinâmicas, as mulheres ainda ficam praticamente sozinhas com as responsabilidades das tarefas domésticas (que, por vezes, são auxiliadas e/ou substituídas pelas filhas meninas). Essa é a esfera em que elas têm um nível de poder na escolha e no preparo das refeições, bem como no cuidado da casa e das roupas, na educação dos filhos, entre outras atividades que são consideras secundárias.

Além disso, essas tarefas são direcionadas de acordo com supostas qualidades, atribuídas às mulheres de acordo com a construção histórica e socialização (de base patriarcal), como: capacidade de executar tarefas repetitivas e tediosas; eficácia de realizar várias tarefas ao mesmo tempo; potencial de associar o trabalho produtivo com o trabalho doméstico; aceitação de remuneração inferior; disponibilidade para trabalhos temporários; maior docilidade, inclusive para fazer reinvindicações (não trazendo muitos conflitos na relação de trabalho). Nessas práticas, perpassam à submissão e obediência das mulheres aos homens da família, seja o marido ou o pai (ViIlwock et al., 2016).

Tardin (2012) aponta as marcas do patriarcalismo no território rural, descrito como um paradigma histórico hegemônico nas sociedades. Faleiro e Farias (2017) afirmam que o patriarcado se refere a "um modo de organização das relações sociais, cuja lógica de divisão de trabalho entre homens e mulheres direciona o que cada gênero deve e pode fazer, conferindo-lhes espaços e atividades determinadas, geralmente tidas como naturais" (p. 837). Entende-se o homem como chefe da família e que exerce poder em relação aos outros membros, de forma semelhante da relação entre o chefe latifundiário e seus subordinados (Almeida, 2010; Tardin, 2012).

Assim, há a supremacia do homem nas relações familiares, nas representações dos espaços públicos, nas manifestações de violência econômicas, morais e físicas, que podem levar a um sentimento de inferioridade física e subjetiva da mulher. Tardin (2012) coloca que, na cultura do campo, essas relações possuem uma grande complexidade por, primeiramente, haver um lugar do homem enquanto figura de autoridade, força, trabalho, honra e bravura, que imprime essa ideia 
de superioridade; e, segundo, por existir uma marca do lugar da família sob a forma europeia cristã hegemônica, em que o homem tem centralidade no pensar e agir sobre os demais.

Um aspecto dessa trama é em relação à violência doméstica contra as mulheres rurais. Em pesquisa realizada por Grossi e Coutinho (2017), é evidenciado que essas mulheres têm mais dificuldades de acessar os serviços e redes de proteção contra a violência doméstica. Há ausência histórica de políticas públicas elaboradas, pensadas e localizadas para e no território rural, pois essas mulheres percorrem quilômetros em busca de apoio, o que impacta também na falta de informação sobre as redes de apoio.

A partir dos conceitos da feminista estadunidense Nancy Fraser (2002, 2006), nota-se que os marcadores sociais que perpassam o ser mulher e viver no território rural impactam na produção de injustiças na dimensão da redistribuição e do reconhecimento, produzindo disparidades de participação social. A injustiça de redistribuição é marcada pela subordinação econômica, que nega aos atores, no caso as mulheres camponesas, sobretudo pobres, os meios e os recursos que necessitam para a paridade de participação por meio da exploração (expropriação do trabalho), privação (não ter o acesso à vida material adequado) e marginalização (trabalho mal remunerado). E a injustiça de reconhecimento atrela-se a uma subalternização cultural ou simbólica, que produz o não-reconhecimento ou o reconhecimento inapropriado, a partir de padrões culturais que perpassam a dominação cultural (que submete a valores hegemônicos de cultura), o não-reconhecimento/ocultamento (que torna invisíveis suas práticas sociais) e o desrespeito (a desqualificação social).

Assim, entende-se que as mulheres rurais têm suas vivências limitadas por essas questões. Tais vivências são limitadas justamente por elas serem mulheres, dentro de uma cultural patriarcal, e por viverem em um território rural, espaço historicamente negligenciado em bens sociais, como o acesso à educação.

\section{Metodologia}

Trata-se de pesquisa qualitativa, tendo em vista que esse método não visa apresentação numérica, mas um entendimento mais profundo quanto aos fatores sociais de grupos (Silva \& Córdova, 2009). Nesse sentido, Minayo (2001) afirma que a pesquisa qualitativa visa o entendimento de fenômenos sociais e seus significados, crenças, motivos e valores.

Para a produção dos dados foi realizado um grupo focal, que pode ser entendido como instrumento para a pesquisa qualitativa, realizado por meio da formação de grupos pequenos, para avaliar fenômenos e identificar problemas (Caplan, 1990). Johnson (1994) menciona que a realização de grupos focais é uma alternativa para o levantamento de várias visões e possibilidades quanto a uma situação vivida pelo grupo. Isso pode resultar em respostas mais abrangentes, pois a interação do grupo potencializa maior número de diálogos e informações, bem como uma visão mais coletiva das respostas.

Neste sentido, foi realizado o grupo focal em um encontro com cinco mulheres camponesas (os nomes usados ao 
longo da discussão são fictícios, para manutenção do anonimato delas), que durou duas horas e vinte minutos. Este encontro aconteceu na comunidade em que elas viviam, em uma casa cedida por uma das participantes.

Os critérios para a seleção das mulheres perpassaram principalmente as relações de proximidade da pesquisadora e dos pesquisadores com estas, tendo em vista que a mulher pesquisadora e coautora desse artigo era estudante da instituição pesquisada, sendo colega das interlocutoras do estudo. Os outros pesquisadores e coautores eram, respectivamente, pós-graduando e docente da instituição. Assim, todos tinham uma relação com essas mulheres, que foram convidadas a integrar a investigação.

Todas as mulheres viviam em uma comunidade rural (não será citado o nome da comunidade, para fins de manutenção do anonimato das mulheres), que é formada por pequenos proprietários, no município de Catalão - Goiás (Brasil). Ademais, todas ingressaram na Licenciatura em Educação do Campo na Universidade Federal de Goiás/Regional Catalão.

Como disparadores para o grupo focal utilizou-se o curta-metragem Vida Maria (Vida de Maria, 2017); seguido da música O chão só dá, se a gente plantar, do compositor Jair Peres; e, por fim, uma dinâmica do texto Carta aberta das Mães Sem Terra (autora desconhecida). Essas foram estratégias encontradas para trazer narrativas culturais que discursavam a respeito de mulheres do campo, a fim de iniciar e fomentar a discussão. Assim, o grupo foi disposto em círculo, e iniciou-se o diálogo amparado por perguntas semiestruturadas. Cabe salientar que toda a condução do grupo focal foi devidamente gravada e, posteriormente, transcrita para realização da análise dos dados.

A análise de dados foi realizada a partir da Análise de Conteúdo, em que se buscou "compreender as mensagens para além dos seus significados imediatos" (Bardin, 1977, p. 29).

Em relação aos princípios éticos, todas as participantes foram esclarecidas dos objetivos e métodos utilizados. Além disso, foi apresentado um Termo de Consentimento Livre e Esclarecido para participação no estudo, que após o aceite foi assinado por cada uma delas.

\section{Resultados e discussão}

As cinco mulheres camponesas iniciaram os estudos acadêmicos no curso de Licenciatura em Educação do Campo da Universidade Federal de Goiás/Regional Catalão. Porém, uma desistiu do curso, e as outras quatro continuam os estudos.

Primeiramente, é interessante delinear o perfil dessas mulheres. Quatro são do estado de Goiás (Brasil), nascidas no município de Catalão, e uma do estado de Maranhão (Brasil). A faixa etária referente às participantes se encontra entre 35 e 48 anos. Todas são casadas e moradoras da comunidade rural em questão. Em relação ao perfil profissional: uma é auxiliar de serviços gerais e outra é secretária pedagógica, ambas da escola da comunidade rural em que vivem. Outras duas trabalham em casa, e a última é trabalhadora da área da saúde.

A partir desses dados e dos diálogos compreende-se que são mulheres da classe trabalhadora, que integram o que 
Antunes e Alves (2004) denominam de classe-que-vive-do-trabalho. Isto é, compõem um grupo que vende sua força de trabalho, tensionadas pela lógica do capital-trabalho, e vivenciam um cotidiano mediado pelas explorações e limitações dadas pela divisão de classes. Ou seja, fala-se aqui de mulheres rurais pobres, sendo esse mais um marcador social da diferença que atravessa, intensamente, suas trajetórias.

Diante disso, é possível compreender melhor as narrativas dessas mulheres na universidade, bem como algumas dificuldades que envolvem os intercruzamentos entre as marcas de gênero e território, e, como visto, a classe social.

\section{"Rompendo as porteiras para poder construir algo diferente": a busca por novas possibilidades de vida}

É possível inferir que, dentre as participantes, o entendimento real acerca do papel da mulher na sociedade e, sobretudo, no território rural, se encontra associado ao seu empoderamento, compreendido como maior aquisição de poder pessoal para "superação de conflitos e a ressignificação das relações sociais, possibilitando a revisão de papéis e de sentidos na produção da vida cotidiana" (Kleba \& Wendausen, 2009, p. 733). Isso ocorre pelo fato de assumir a capacidade de ir à luta, de romper porteiras e barreiras quando mencionam que:

Ser mulher aqui (em sua comunidade) é estar vencendo as dificuldades do dia a dia e rompendo cada uma dessas dificuldades, rompendo as porteiras para poder construir algo diferente (Ana).
Assim, compreende-se que essas mulheres se colocam em um lugar de luta cotidiana, que dentro dos condicionamentos sociais postos assumem um vir a ser voltado para ações, a fim de romper e construir algo diferente do estruturado pelo status quo. Isso remete a uma luta histórica das mulheres camponesas, que é reafirmado nos documentos do Movimento de Mulheres Camponesas: "Ao longo da história somos nós, mulheres camponesas, indígenas, negras e da floresta que estamos preservando as sementes e produzindo alimentos e cuidando da natureza. Somos nós que ainda resistimos e enfrentamos o dia a dia" (Movimento de Mulheres Camponesas [MMC], 2007, p. 7-8). Aponta-se, assim, para as brechas que essas encontram para resistir e buscar formas de emancipação. Nas falas, aparece fortemente uma mudança geracional, sinalizada como um marcador importante:

Mulher, antigamente para o homem, é para ser mãe dos filhos dele e cuidar de casa! (Maria).

Assim sendo, historicamente o ser mulher se encontra relacionada à inferioridade, às atividades domésticas, à submissão, à fragilidade, às limitações da vida no campo etc. Porém, a partir da fala de Maria identifica-se mudanças históricas. Esse estereótipo tem sido, tendo em vista a luta das mulheres, abandonado a partir de algumas mudanças em nível de reconhecimento e redistribuição, dando lugar a possibilidades de ser mulher e assumir outros papéis sociais, superando a imposição sexista e machista.

Isso pode ser analisado por meio do impacto do feminismo enquanto luta histórica. Fraser (2006) identifica que esse movimento de luta toma outra pro- 
porção, sobretudo no final do século XX, em que reivindica o reconhecimento da diferença. Zamboni (2014) registra que isso se intensifica na segunda metade do século XX. No Brasil, mais especificamente no período de redemocratização do país, há forte aliança de movimentos feministas, negros, sindicais, homossexuais, entre outros. Há também a força dos movimentos autônomos das próprias mulheres camponesas desde o início da década 1980 (Cinelli \& Jahn, 2011), destacando-se aqui o Movimento de Mulheres Camponesas, consolidado em 2004, fruto da unificação de grupos estaduais, que tem como missão:

a libertação das mulheres trabalhadoras de qualquer tipo de opressão e discriminação. Isso se concretiza nas lutas, na organização, na formação e na implementação de experiências de resistência popular, onde as mulheres sejam protagonistas de sua história. Lutamos por uma sociedade baseada em novas relações sociais entre os seres humanos e deles com a natureza (MMC, 2007, s.p).

A partir disso, outra colocação interessante é como essas mulheres percebem as mudanças, entendendo-as como fruto dessas lutas históricas:

Eu acho que pelos próprios homens terem mudado né? Novos conhecimentos, e eles apoiam mais as mulheres. [...] o apoio do marido, as mulheres também podem sair, podem correr atrás, não vai fazer nenhum mal que as mulheres possam sair, trabalhar, estudar também né? Acho até que eles evoluíram (Ana).

Assim, Ana relata que percebe uma mudança dos próprios homens, que, no caso os maridos, passam a apoiar mais os projetos das mulheres para além dos condicionamentos sociais de gênero. Queiroz \& Bernardino (2014) discorrem que realmente há esses avanços, porém, as mulheres, muitas vezes, não param de assumir os papéis marcados pelos estereótipos, como cuidar das tarefas domésticas. Assim, acabam por acumular tarefas na ordem pessoal, familiar e profissional, sendo urgente repensar criticamente essas atividades feminizadas e invisibilizadas (Grandón-Valenzuela, 2018).

\section{"Antes de ir para a faculdade eu achava que meu mundo era só ali": potências e desafios de estar na universidade}

Evidencia-se que, ao levantar e fomentar discussões relevantes de gênero dentro de uma sociedade, são geradas mudanças, mesmo que condicionadas aos limites estruturais da desigualdade. Essas mudanças acontecem não apenas em relação às pessoas que estão a sua volta, mas quanto à própria visão de mundo individual da mulher, o que incide na busca de direitos e rompimento de barreiras para conquistas em diversos âmbitos, tendo em vista a aquisição de novos saberes. Em relação à universidade a participante Valentina expõe que: Assim, eu acho que ser mulher [...]
não é só a gente viver naquele mun-
dinho da roça, da lida, [...] no meu
exemplo, eu antes de ir para a facul-
dade eu achava que meu mundo era
só ali. Era só cuidar de casa, de filho,
de marido; eu não conhecia o mun-
do lá fora. O que eu conheço hoje, a
experiência que eu tenho hoje né, eu
conheci através da faculdade. Foi que
eu fui primeiramente conhecer o que
são os meus direitos como mulher, os 
meus deveres como mulher, isso tudo eu aprendi na faculdade. $E$, eu creio assim: se eu ficasse no meu mundinho lá em casa só cuidando lar, cuidando lá de casa, eu não ia descobrir essas novas experiências que conheci (Valentina).

Mediante a análise da fala, é possível observar que a mulher do campo sofreu e ainda sofre com a cultura do patriarcado por meio da imposição e divisão dos papéis sociais, produtivos, familiares e políticos, de acordo com o gênero. Porém, a partir da fala de Valentina observou-se que o direito das camponesas à Educação Superior se apresenta como uma grande conquista.

Isso afirma o que foi apresentado no estudo de Faleiro e Farias (2017), que descrevem como o acesso à Educação Superior pode empoderar as mulheres camponesas, subvertendo limitações dos papéis sociais impostos pela cultura patriarcal, possibilitando novas vivências e acesso a conhecimentos que as colocam como protagonistas de suas histórias. Neste sentido, a pesquisa de Froes (2017), realizada com mulheres camponesas universitárias, conclui: "Dessa forma, elas comentaram como, após o ingresso no curso abriram a cabeça, ocasionando uma mudança de percepção e problematização de questões sociais, da posição ocupada por elas, das diversas injustiças sociais" (p. 5).

Na pesquisa de Pereira (2014), se verificou que "em decorrência do acesso à LEdoC (Licenciatura em Educação do Campo), percebe-se sinais de ruptura e emancipação dando novos sentidos e significados à vida dessas mulheres e construindo estratégias de resistência frente às posturas de discriminação" (p.
8), que perpassam, inclusive, o reconhecimento dos seus direitos e as possibilidades de ocupar outros lugares.

Todavia, entre as falas analisadas, a cultura do patriarcado ainda se apresenta como uma das barreiras, afirmando o que é apontado por Queiroz \& Bernardino (2014), que há avanços, mas ainda há a (re)produção de relações de dominação e inferiorização das mulheres:

Muitas mulheres, mesmo que não
sejam do campo, não concluem um
curso de Ensino Superior por causa
do marido mesmo, por não ter apoio,
porque os maridos não deixam, falta
de confiança, ciúmes (Lázara).

Quando engravidei né, ouvi por aí que tinha arrumado esse neném lá na faculdade, que não era filho do meu marido e não sei mais o que, e no final nasceu a cara do pai (Valentina).

As falas de Lázara e Valentina refletem, fortemente, como o patriarcado e o machismo estão impregnados na comunidade camponesa, o que acaba limitando a vida dessas mulheres e causando transtornos.

Afirma-se nas narrativas "que o sentimento de posse, em detrimento do feminino, permeia o cotidiano das mulheres que vivem no campo. As relações conjugais mostram que o exercício do poder ocorre de forma assimétrica, delegando o poder de decisão ao homem" (Grossi \& Coutinho, 2017, p. 34). Mas não só do homem individualmente, mas de toda a comunidade, que reitera a lógica do patriarcado e do machismo, sob a desconfiança que perpassa a gravidez, por exemplo, que colocam essas mulheres como alvo dessas narrativas perver- 
sas. Nesse sentido, Valentina complementa que:

Mas falar o povo fala viu, até os maridos mesmo no começo, por a gente estar saindo dali né, acaba desconfortável, e os outros também, a gente enfrenta muito disso, meu marido já escutou muito disso, 'à mulher que vai para a faculdade é muito é esperta, quer dar o pé no marido, é para isso, é para aquilo' (Valentina).

A universidade é colocada como espaço em que as mulheres querem escapar dos maridos, insinuando aspectos de traição, demarcando como essas mulheres passam a carregar reconhecimentos negativos a partir do momento que decidem optar por caminhos diferentes, que saem do ambiente restrito doméstico e comunitário.

Outro fator identificado é a distância e dificuldade de acesso entre a universidade e o território rural que vivem, que também acaba por reiterar lógicas de exclusão:

Eu comecei e parei, fiz só um $1^{\circ}$ período, o curso era à noite, e onde eu morava não tinha como eu ir (Maria).

Não é fácil são quatro anos de muita luta e muita perseverança, se não a gente desiste mesmo, porque por morar aqui na fazenda no campo, eu acredito que é muito difícil bem mais difícil do que para quem mora lá (Lázara).
A partir das falas das mulheres, ainda se observa que poucas são as ações para a inclusão das camponesas na universidade, como de políticas públicas específicas, que diz respeito ao financiamento, transporte e demais condições estruturais de mobilidade, negligência histórica, como já foi citado anteriormente. Isso reflete, por exemplo, na insuficiência e redução das bolsas-permanência ${ }^{7}$ voltadas para esses estudantes na referida universidade, que, com a ausência de recursos como esse, possuem maior dificuldade de permanecerem nos cursos.

Esse aspecto se agrava na realidade contemporânea do Brasil (especificamente desde 2016), com as políticas de desmonte de direitos sociais, baseado em um projeto neoliberal profundo, acarretando cortes orçamentários que têm atingido a Educação do Campo, inclusive a Licenciatura, com a redução de bolsas-permanência para as estudantes. Isso está associado também à desestruturação de políticas de Agricultura Familiar e políticas específicas para mulheres rurais, entrelaçadas com a potencialização de políticas pautadas em um projeto com base no agronegócio (Castro, 2016; Santos, 2019).

\section{Conclusões}

Observou-se que essas mulheres rurais, que ingressaram na universidade, estão engajadas na luta pelo rompimento das porteiras para poder construir algo diferente, que diz respeito a mudanças cotidianas individuais e coletivas.

\footnotetext{
7 A bolsa-permanência integra o Programa de Bolsa Permanência - PBP, que é uma ação do Governo Federal do Brasil de concessão de auxílio financeiro a estudantes, matriculados em instituições federais de Ensino Superior em situação de vulnerabilidade socioeconômica, e para estudantes indígenas e quilombolas.
} 
Todavia, apesar dos avanços reconhecidos por essas mulheres, refletidos em processos de inserção de forma mais autônoma na sociedade, identifica-se que há, de forma intensa, a (re)produção do patriarcado e do machismo em seus cotidianos, sobretudo quando essas decidem fazer caminhos diferentes, como acessar a universidade, tendo que lidar com alguns conflitos para implementação desses projetos de vida.

Esses conflitos podem envolver: a vida familiar, relacionados às negociações com os maridos, por exemplo; a vida comunitária, lidando com a desconfiança dos vizinhos a respeito do que fazem na universidade; a vida institucional, ligados às insuficiências das ações para inclusão das camponesas na universidade; entre outras questões.

Para alcançar a concepção de justiça social colocada por Fraser (2002; 2006), ainda se requer avanços na redistribuição de poder e no reconhecimento dessas mulheres, superando problemas estruturais que perpassam os marcados sociais de gênero e territorialidade, mas também, fortemente, de classe social. Nesse sentido, a universidade coloca-se como um espaço importante para essas mulheres se empoderarem de suas possibilidades de vida para além do que é imposto, se tornando mais conscientes sobre as opressões que as cercam e as formas de superar tais questões.

Diante do exposto, é possível afirmar que a educação, com vistas à inclusão da mulher do campo na universidade, é um bom caminho para o rompimento das porteiras. Afinal, essa experiência social, cultural, educacional e política pode possibilitar vivências libertadoras e a apropriação de saberes que levam as pessoas ao conhecimento das diversas formas de participação social.

Financiamento: este trabalho foi apoiado pela Coordenação de Aperfeiçoamento de Pessoal de Nível Superior - Brasil (CAPES) - Código de Financiamento 001.

\section{Referências}

Almeida, J. P. (2010). As multifaces do patriarcado: uma análise das relações de gênero nas famílias homoafetivas [dissertação de mestrado, Universidade Federal de Pernambuco].

Antunes, R., \& Alves, G. (2004). As mutações no mundo do trabalho na era da mundialização do capital. Educação \& Sociedade, 25 (87), 335-351. https://doi.org/10.1590/ $\underline{\text { S0101-73302004000200003 }}$

Bardin, L. (1977). Análise de conteúdo. Edições 70.

Brumer, A. (2004). Gênero e agricultura: a situação da mulher na agricultura do Rio Grande do Sul. Estudos Feministas, 12 (1), 205 - 227. https://doi.org/10.1590/S0104026X2004000100011

Caldart, R. S. (2019). Concepção de Educação do Campo: um guia de estudo. In M. C. Molina \& M. F. A. Martins (Eds) Formação de formadores: Reflexões sobre as experiências da Licenciatura em Educação do Campo no Brasil (pp.5577). Autêntica Editora. 
Caplan, S. (1990). Using focus group methodology for ergonomic design. Ergonomics, 33(5), 33-527.

Castro, E. G. (2016). PNRA e juventude rural: 30 anos depois-balanço e apontamentos em um contexto de ruptura institucional. Retratos de Assentamentos, 19(2), 98-124. https://doi.org/10.25059/2527-2594/retratosdeassentamentos/2016.v19i2.240

Cinelli, C., \& Jahn, E. F. (2011). A constituição de identidades camponesa e feminista no Movimento de Mulheres Camponesas. Revista Espaço Acadêmico, 10 (117), 86-92.

Faleiro, W., \& Farias, M. N. (2017). Inclusão de mulheres camponesas na Universidade: entre sonhos, desafios e luta. Educação e Pesquisa, 43 (3), 833-846. http://dx.doi. org/10.1590/s1517-9702201707168124

Farias, M. N, \& Faleiro, W. (2019). Princípios do Movimento de Educação do Campo: análise dos Projetos Político-Pedagógicos das LEdoCs do Centro-Oeste brasileiro. Editora Navegando.

Fraser, N. (2006). Da redistribuição ao reconhecimento? Dilemas da justiça numa era "pós-socialista". Cadernos de Campo, 15(14/15), 231-239. https://doi. org/10.11606/issn.2316-9133.v15i1415p231-239

Fraser, N. (2002). Redistribuição ou reconhecimento? Classe e status na sociedade contemporânea. Interseções - Revista de Estudos Interdisciplinares, 4 (1), 7-32.

Froes, L. T. (2017). Da roça à Universidade: trajetórias de mulheres no curso de licenciatura em educação do campo da UFMG. Anais Seminário Internacional Fazendo Gênero 11 \& 13th Women's Worlds Congress.
Godoi, E. P., \& Aguiar, V. V. P. (2018). Mulheres e territórios vividos em contextos rurais: um olhar sobre a política de desenvolvimento territorial. Cadernos pagu, (52), 1-35. http://dx.doi.org/10.1590/1809444920180 $\underline{0520007}$

Gomes, R. C. M., Nogueira, C., \& Toneli, M. J. F. (2016). Mulheres em contextos rurais: um mapeamento sobre gênero e ruralidade. Psicologia \& Sociedade, 28 (1), 115-124. http://dx.doi.org/10.1590/1807-03102015 v28n1p115

Grandón-Valenzuela, D. (2018). Función económica de las ocupaciones feminizadas no remuneradas: una crítica desde la economía feminista. Revista Ocupación Humana, 18 (2), 54-67. https://doi. org/10.25214/25907816.228

Grossi, P. K., \& Coutinho, A. R. C. (2017). Violência contra a mulher do campo: desafios às políticas públicas. Serviço Social em Revista, 20(1), 25-40. http://dx.doi.org/10.5 433/1679-4842.2017v20n1p25

Heredia, B. M. A., \& Cintrão, R. P. (2006). Gênero e acesso a políticas públicas no meio rural brasileiro. Revista Nera, 8(9), 01 -28. https://doi.org/10.47946/rnera.v0i8.1443

Instituto de Pesquisa Econômica Aplicada [IPEA] (2012). Educação. Políticas Sociais: acompanhamento e análise. Ipea.

Instituto de Pesquisa Econômica Aplicada [IPEA] (2017). Educação. Políticas Sociais: acompanhamento e análise. Ipea.

Johnson, D. (1994). Focus Groups. In D. Zweizig et al. (orgs). Tell it! Evaluation sourcebook \& training manual (pp.161-172). SLIS. 
Kleba, M. E., \& Wendausen, A. (2009). Empoderamento: processo de fortalecimento dos sujeitos nos espaços de participação social e democratização política. Saúde e Sociedade, 18(4), 733-743. https://doi. org/10.1590/S0104-12902009000400016

Leite, S. C. (1999). Escola rural: urbanização e políticas educacionais. Editora Cortez.

Melo, K. M. M., Malfitano, A. P. S., \& Lopes, R. E. (2020). Os marcadores sociais da diferença: contribuições para a terapia ocupacional social. Cadernos Brasileiros de Terapia Ocupacional, 28(3), 1061-1071. https:// doi.org/10.4322/2526-8910.ctoARF1877

Minayo, M. C. S. (2001). Pesquisa Social. Teoria, método e criatividade (18 ed.). Editora Vozes.

Movimento de Mulheres Camponesas [MMC] (2007). Cartilha base. MMC Brasil. http:// www.mmcbrasil.com.br/site/materiais/ download/cartilha_tbase2007.pdf.

Molina, M. (2015). Expansão das licenciaturas em Educação do Campo: desafios e potencialidades. Educar em Revista, (55), 145-166.

Observatório do Plano Nacional de Educação [OPNE] (2019). 12 - Educação Superior. Observatório do PNE. https://www. observatoriodopne.org.br/indicadores/ metas/12-ensino-superior/indicadores/ porcentagem-de-matriculas-da-populacao-de-18-a-24-anos-na-educacao-superior/162/

Pereira, M. L. S. (2014). As contribuições da Licenciatura em Educação do Campo na transformação das relações de gênero: um estudo de caso com as educandas do Assentamento Virgilândia de Formosa/GO [dissertação de mestrado, Universidade de Brasília].
Pereira, M. L. S. (2016). As contribuições da licenciatura em Educação do Campo na transformação das relações de gênero. $R e-$ vista com censo, 3 (4), 40-46.

Queiroz, C. S., \& Bernardino, A. V. S. (2014). Mulheres e a igualdade de gênero no Século XXI: Realidade ou mera utopia? Revista Mosaico, 5 (2), 11-14. https://doi. org/10.21727/rm.v5i2.191

Santos, C. A. (2019). A educação do campo e o fim das políticas públicas como as conhecemos: questões para reflexões de futuro. $R e-$ vista de Políticas Públicas, 23 (2), 501-513.

Silva, J. F., Torres, D. X., \& Lemos, G. T. (2012). Educação do campo: a luta dos movimentos sociais campesinos por uma educação escolar específica e diferenciada. Revista Pedagógica - UNOCHAPECÓ, 1 (28), 409-438. https://doi.org/10.22196/ rp.v14i28.1373

Silveira, D. T., \& Córdova, F. P. (2009). A pesquisa científica. Em T. E. Gerhardt \& D. T. Silveira (eds.), Métodos de pesquisa (pp. 31-42). Editora da UFRGS.

Tardin, J. M. (2012). Cultura camponesa. In R. Caldart et al. (Eds.), Dicionário da educação do campo (pp. 178-186). Expressão Popular.

Vida de Maria (2017). Canal Vida de Maria [YouTube]. https://www.youtube.com/watch?v=yFpoG htum4\&t=193s.

Villwock, A. P. S., Germani, A. R. M., \& Roncato, P. E. S. (2016). Questões de gênero no mundo rural e na extensão rural brasileira. Revista Alamedas, 4(1), 01-17.

Zamboni, M. (2014). Marcadores sociais da diferença. Sociologia: Grandes Temas do Conhecimento (Especial Desigualdades), 1, 14-18. 